\title{
Fabrication of composites based on modified vermiculite and study of their surface
}

\author{
(C) Nikolay P. Shapkin, ${ }^{1}{ }^{*}$ Irina G. Khalchenko, ${ }^{1}$ Larisa I. Sokolova, ${ }^{1}$ \\ Anton L. Shkuratov, ${ }^{1}$ Valery I. Razov, ${ }^{1}$ Daria S. Galchenko, \\ Maria G. Smirnova, ${ }^{1}$ Svetlana A. Katkova, ${ }^{2}$ and Olga A. Apanasenko ${ }^{1}$ \\ ${ }^{1}$ School of Natural Sciences. Far Eastern Federal University. Sukhanova St., 8. Vladivostok, 690950. \\ District Primorsky.Russia.Phone: +7 (902)057-76-08.E-mail:npshapkin@gmail.com \\ ${ }^{2}$ Department of Chemistry. Far Eastern State Technical Fisheries University. \\ Meadow, St., 52B. Vladivostok, 690087. District Primorsky. Russia. \\ Phone: +7 (423) 244-03-06.E-mail:festfu@mail.ru
}

\begin{abstract}
*Supervising author; ${ }^{+}$Corresponding author Keywords: vermiculite modification, sorption properties, antibiotic sorption.
\end{abstract}

\begin{abstract}
Composites based on vermiculite with different modifiers, including hydroxides on the surface of vermiculite particles, have been fabricated. The composition and structure of the fabricated composites have been investigated by means of the methods of energy-dispersive analysis, X-ray diffraction analysis, and positron annihilation spectroscopy. The adsorption characteristics of the fabricated materials with respect to dye of different nature have been determined, and isotherms of low temperature nitrogen adsorption/ desorption have been obtained. It has been demonstrated that for different modifications the composites sorption properties change significantly in dependence on the modifier nature. At modification of layered natural aluminosilicates by cellulose and polyethylene, the surface nature depends largely on the modifier nature. At treatment by polyethylene, a dramatic decrease of the aluminosilicate surface area due to formation of a dense film takes place. The effect of cellulose is not so significant because of formation of a looser surface structure. The sorption characteristics somewhat improve upon further annealing.

Good prospects of application of the fabricated sorbents for antibiotics sorption and analytical determination in food products have been demonstrated. Vermiculite, modified with 7\% hydrochloric acid, demonstrates a high degree of absorption for chloramphenicol, tetracycline, ciprofloxacin and cefazolin antibiotics. The values of the degrees of absorption show: $73 \%,>99 \%,>99 \%$ and $73 \%$, respectively. The degree of elution for chloramphenicol is more than $75 \%$, which allows you to create concentrated cartridges based on this sorbent. The degree of elution is low, which allows the use of a sorbent based on vermiculite for the treatment of waste and natural waters from these antibiotics.

\section{References}

[1] A.Yu. Godymchuk, A.P. Ilyin. Water Chemistry and Technology. 2004. Vol.26. No.3. P.287. (russian)

[2] L.I. Bel'chinskaya, O.Yu. Strel'nikova, L.A. Novikova, F. Ressner, O.V. Vioshcheva. Protection of Metals. 2008. Vol.44. No.4. P.390. (russian)

[3] Yu.A. Leikin, T.A. Cherkasova, N.A. Smagina. Sorption and Chromatographic Processes. 2009. Vol.9. No.1. P.104. (russian)

[4] M. Alexandre, Ph. Dubois. Materials Science and Engineering. R: Reports. 2000. Vol.28. No.1-2. P.1.

[5] E.M. Antipov, M.A. Guseva, V.A. Gerasin, Yu.M. Korolev, A.V. Rebrov, H.R. Fischer, I.V. Razumovskaya. Polymer Science Series A. 2003. Vol.45. No.11. P.1130. (russian)

[6] N.P. Shapkin, I.G. Khal'chenko, A.E. Panasenko, L.B. Leont'ev, A.A. Yudakov, V.I. Sergienko, V.Y. Maiorov. Inorganic materials. 2017. Vol.53. No.10. P.1091.

[7] L.A. Marchenko, A.A. Marchenko. Sorption and Chromatographic Processes. 2009. Vol.9. No.6. P.868. (russian)

[8] Yu.I. Taraswevich, F.D. Ovcharenko. Adsorption on Clay Minerals. Kiev: An SSSR. 1975.

[9] I.G. Khalchenko, N.P. Shapkin, A.L. Shkuratov. Water practice and technology. 2017. Vol.12. No.1. P.117.

[10] I.G. Khalchenko, N.P. Shapkin, I.V. Svistunova, E.A. Tokar. International Scientific Forum Butlerov Heritage - 2015. Butlerov Communications. 2015. Vol.41. No.1. P.74-82. DOI: 10.37952/ROI-jbc-01/15-41-1-74
\end{abstract}

Kazan. The Republic of Tatarstan. Russia. (C) Butlerov Communications. 2019. Vol.58. No.6. 
[11] N.P. Shapkin, N.N. Zhamskaya, S.A. Katkova. Bull. Higher Education Inst. Food Technology. 2010. Vol.1. P.110. (russian)

[12] K.O. Belyustova, L.I. Sokolova. Food Processing: Techniques and Technology. 2011. Vol.3. No.22. P.107. (russian)

[13] L.I. Sokolova, N.P. Shapkin, K.O. Belyustova. Pat. 2431829 Russian Federation. 2010.

[14] Yu.O. Privar, L.I. Sokolova, K.O. Belyustova, N.P. Shapkin, V.B. Kolycheva. Proceedings of the academic conference in English of school of natural science students. Vladivostok: FEFU. 2014. P.59.

[15] N.N. Zhamskaya, S.A. Mashkova, L.S. Buankina, N.P. Shapkin. Bull. Far East Technical Fisheries University. 2008. Vol.20. P.37. (russian)

[16] N.P. Shapkin, V.Yu. Maiorov, L.B. Leont'ev, A.L. Shkuratov, V.Ya. Shapkina, I.G. Khal'chenko. Colloid Journal. 2014. Vol.76. No.6. P.746. (russian)

[17] A.L. Shkuratov, N.P. Shapkin, I.G. Khal'chenko, V.I. Razov, L.B. Leont'ev, I.M. Ermak. Journal of bionanoscience. 2016. Vol.10. No.5. P.430.

[18] L.B. Leont'ev, N.P. Shapkin, A.L. Leont'ev, V.N. Makarov, A.G. Toklikishvili. Tribotechnical Nanomaterials and Reliability of Marine Diesels. Vladivostok: FEFU. 2017. (russian)

[19] W. Brandt. Applied Physics. 1974. Vol.5. No.1. P.1. 